Thank you for your participation.

Enter your email address below for a chance to winone of two $50 \$$ Starbucks gift cards. Otherwise, your email address, personal information and IP address will not be recorded. All answers will remain anonymous and confidential. There are no risks to participating in this survey and the University of Manitoba Health Research Ethics Board has approved the study.

If you have any questions about this study, please contact us at delislem@myumanitoba.ca.

By continuing on and completing the survey you are consenting to participate.

1. Enter email address (optional) 


\section{About you}

$* 2$. Are you male or female?
Female
Male

* 3 . What is your age (years)?

$<=20$

21-25

26-30

31-35

$36-40$

$>>40$

$* 4$. What year of residency training are you in?
1
2
3
4
5
6
$>1=7$ 
* 5. Approximately how many residents are in your program?

Do not know

0-10

(11-20

21-30

$31-40$

$41-50$

(51-60

$>/=61$ 


\section{Mentoring in Surgery}

\section{What do we mean by mentoring?}

The process whereby a more experienced, usually senior, individual (the mentor) guides the personal and professional development of someone more junior (the mentee).

* 6 . What is your perspective on mentors in surgery?

Critical to my training

Beneficial, but not critical to my training

Not important to my training

Obstructive to my training

Neutral/no opinion 
Mentoring in Surgery

* 7. How many mentors do you have?

0
1
2
$>l=3$




\section{Mentoring in Surgery}

\section{* 8. Which of the following best describes mentorship in your program?}

A formal mentorship program exists (i.e. formal documentation of encounters)

An informal mentorship program exists (i.e. no formal or required documentation)

No program exists

Unsure

* 9. Mark all resources available for mentorship in your residency program:

Protected time for meetings

Merit for outstanding mentors

Objectives for mentors and/or mentees (i.e. suggested meeting frequency)

Case discussions and readings to stimulate discussion

List of available mentors

Interest based matching process

Not aware of any

$\square$ Other (please specify) 
Mentoring in Surgery

* 10. How often are you required to communicate with your mentor?
Weekly
Monthly
Each rotation
Every six months
Yearly
Ad-hoc/ no requirement
Other (please specify) 
Mentoring in Surgery

* 11. How often do you communicate with your mentor?

$\bigcirc$ Weekly

Monthly

Each rotation

Every six months

Yearly

Ad-hoc

Other (please specify) 


\section{Mentoring in Surgery}

* 12. How did you obtain your mentor?

Assigned by institution, program director, etc.

Obtained on my own

Was approached by mentor

Recommended by a colleague

* 13. Which of the following best describes your mentor(s)? (mark all that apply)

More senior resident than yourself

Fellow

Attending

Program director

Other (please specify) 
Mentoring in Surgery

* 14 . What year of residency was your mentor assigned?

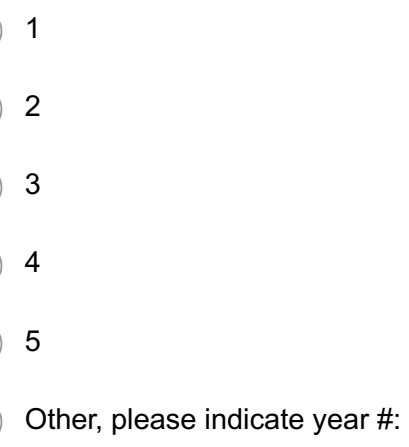


Mentoring in Surgery

$* 15$. What year of residency did your mentor approach you?

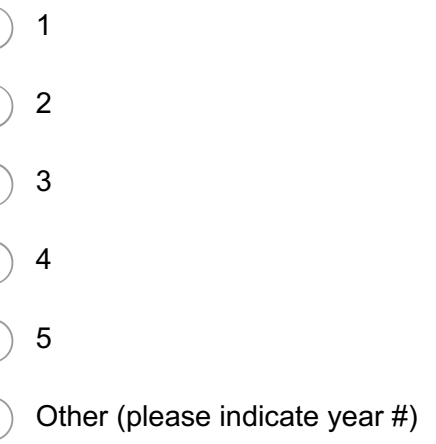




\section{Mentoring in Surgery}

* 16. What year of residency did you obtain a mentor of your own?

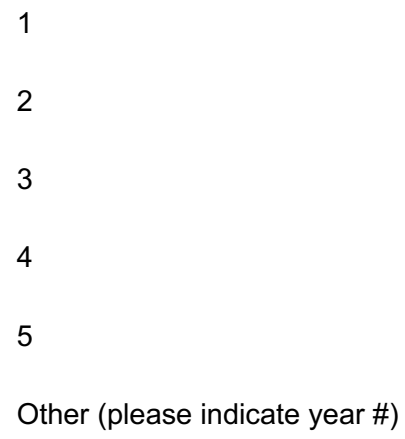

* 17. Why did you obtain a mentor on your own (mark all that apply):

Mentor was studying area of interest in research

Mentor fulfilled my need for a research adviser

Mentor was easy to work with/approachable

Person had a good reputation as a mentor

Mentor was in sub-specialty I was interested in

Mentor had a practice environment that I saw as ideal

I wanted to get a job

Other (please specify) 


\section{Mentoring in Surgery}

* 18. What reason(s) was your mentor recommended to you (mark all that apply):

Mentor was studying area of interest in research

Mentor fulfilled my need for a research adviser

Mentor was easy to work with/approachable

Person had a good reputation as a mentor

Mentor was in sub-specialty I was interested in

Mentor had a practice environment that I saw as ideal

I wanted to get a job

Other (please specify) 


\section{Mentoring in Surgery}

* 19. Through what format does your mentoring most commonly take place?

Telephone

Email

Face-to-face

Audio/teleconferance (e.g. Skype, FaceTime)

Text message/imessage/instant message

Other (please specify)

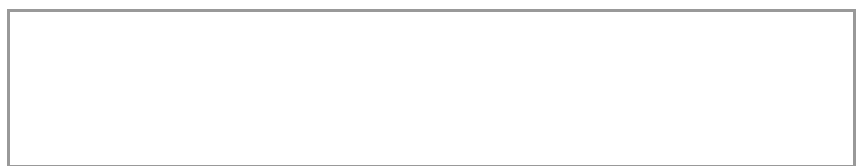

* 20. Are you aware of your mentor having received training in mentorship/leadership/communcation?

Yes

No

Do not know

* 21. How long has this mentoring relationship existed?

0-5 months

6-11 months

1-3 years

4-5 years

$>6$ years 


\section{Mentoring in Surgery}

* 22. Please identify the reason(s) for not having a mentorship relationship (mark all that apply):

Time constraints

Generational gap

Personality conflicts

Opposite gender available, prefer same gender

Same gender available, prefer opposite gender

Scarcity of qualified mentors

Cannot identify someone who truly reflects what you need

Do not want someone who is also an educational supervisor

$\square$ Other (please specify) 


\section{Mentoring in Surgery}

* 23. Which of the following best describes mentorship in your residency program?

A formal mentorship program exists (i.e. formal documentation of encounters)

An informal mentorship program exists (i.e. no formal or required documentation)

No program exists

Unsure

* 24. What resources are available for mentorship in your program? (mark all that apply)

Protected time for meetings

Merit for outstanding mentors

Objectives for mentors and/or mentees (i.e. suggested meeting frequency)

Case discussions and readings to stimulate discussion

List of available mentors

Interest based matching process

Not aware of any

Other (please specify) 
Outcomes of mentoring

* 25. Indicate which of the following you agree/disagree with:

My mentor was...

strongly
disagree
Accessible
Professional
A content expert
Approachable
Supportive
Motivating

Other (please specify) 
Outcomes of Mentoring

* 26. Indicate which of the following you agree/disagree with:

My mentor provided...

Constructive critiques
Guidance on
professional issues
Satisfactory answers
and resources
Acknowledgement of
your contributions
Guidance on personal
issues

Other (please specify) 


\section{Outcomes of Mentoring}

* 27. Overall, how satisfied you are with your mentorship relationship:

Not satisfied

Neutral

Satisfied

* 28. What are the problem(s) with your current mentor-mentee relationship? (mark all that apply)

Time constraints

Generational gap

Personality conflict

Opposite gender, prefer same gender

Same gender, prefer opposite gender

Scarcity of qualified mentors

Assigned someone who does not truly reflect what you need

Assigned someone who is also an educational supervisor

None

Other (please specify) 
Ideal Mentorship

* 29. Select all attributes of an ideal mentor that are important to you: (mark all that apply)

Works in General Surgery or a General Surgery sub-specialty

Same ethnicity and/or religion

Same gender

Similar generation as you

Is a clinical academic

Is also your educational supervisor

Someone who is chosen by you

Someone who is allocated to you

Does not have an influence on your academic standing

Other (please specify)

$* 30$. You would like a mentor to help with the following aspect(s): (mark all that apply)

Professional development

Career decisions

Academic/research

Exam performance

Operative skills

Clinical confidence

Personal life

Other (please specify) 
Ideal Mentorship

* 31. Select resource(s) that would facilitate the development of a mentorship relationship? (mark all that apply)

Protected time for meetings

Merit for outstanding mentors

Objective for mentors and/or mentees (i.e. suggested meeting frequency)

Case discussion and readings to stimulate discussions

List of available mentors

Interest based matching process

Other (please specify)

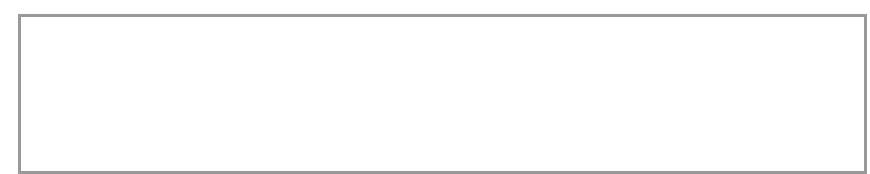

* 32. What should a mentoring program be?

Required and monitored by residency program

Required but not monitored by residency program

Not required by residency program

Other (please specify) 